\title{
A GESTÃO DA CADEIA DE SUPRIMENTOS NA NACIONALIZAÇÃO DE EQUIPAMENTOS PARA NAVEGAÇÃO: O PAPEL DA MARINHA DO BRASIL
}

\author{
Antonio Jorge Telles de Menezes Dantas \\ Diretoria de Sistemas de Armas da Marinha \\ Rua $1^{\circ}$ de Março $118,21^{\circ}$ andar, Rio de Janeiro (RJ) \\ antonio.jorge@dsam.mar.mil.br \\ Claudio Pitassi \\ IBMEC \\ Av. Presidente Wilson, $118,10^{\circ}$ andar, Rio de Janeiro (RJ) \\ claudio.pitassi@gmail.com \\ Marco Aurélio Carino Bouzada \\ Universidade Estácio de Sá (Mestrado em Administração e Desenvolvimento Empresarial) \\ Av. Presidente Vargas, $642-22^{\circ}$. Andar - Centro - Rio de Janeiro (RJ) \\ marco.bouzada@estacio.br
}

\begin{abstract}
Resumo
O presente estudo qualitativo abordou a nacionalização de equipamentos comerciais para navegação marítima, sob o prisma da gestão da cadeia de suprimentos da Marinha do Brasil, pesquisando, em particular, a logística de abastecimento dos referidos equipamentos, e o processo de desenvolvimento de fornecedores, detentores de potencial e interesse para manufaturar equipamentos utilizáveis em navios de guerra, com alto índice de componentes nacionalizados. As informações extraídas de entrevistas com elementos da Marinha e de uma empresa selecionada identificaram expectativas, riscos, requisitos para seleção de parceiros comerciais e condições básicas para uma empreitada de nacionalização frutificar, além de possíveis mercados onde os produtos nacionalizados possam ser comercializados, inclusive em outros países. O estudo conclui com a necessidade de estabelecimento de políticas públicas integradas, que proporcionem suporte orçamentário constante e adequado ao reaparelhamento da Marinha, e que motivem a indústria nacional a realizar parcerias bem sucedidas com as Forças Armadas, apoiadas pela participação perene do Governo Federal.

Palavras-Chaves: Gestão da cadeia de suprimentos; Nacionalização; Desenvolvimento de fornecedores; Logística.
\end{abstract}

\begin{abstract}
The present qualitative study addressed the nationalization of commercial equipment for maritime navigation from the perspective of the supply chain management of the Brazilian Navy, researching in particular the logistics of supply of the equipments, and the suppliers development process, with potential technical expertise and interest to manufacture equipments that can be used by warships, with high percentage of nationalized components . Information extracted from interviews with members of Brazilian Navy and a selected company identified expectations, risks, requirements for selection of business partners and the basic conditions for a fruitful nationalization enterprise, and possible markets where nationalized products can be presented, including other countries. The study concludes with the need for establishment of integrated public policies that provide constant and adequate budgetary support to the modernization of the Navy, and that encourage Brazilian industry to realize successful partnerships with the armed forces, supported by the perennial interest of the Federal Government.
\end{abstract}

Keywords: $\quad$ Supply chain management; Nationalization ; Suppliers development ; Logistics. 


\section{INTRODUÇÃO}

Há décadas o Brasil busca alcançar um papel de maior destaque na geopolítica regional e mundial, destacando-se nesse objetivo a ambição abertamente declarada de o país integrar permanentemente o Conselho de Segurança da Organização das Nações Unidas (ONU). Para que isso ocorra, o Brasil deverá melhor aparelhar suas Forças Armadas. Nessa linha de argumentação, destaca-se em Brasil (2008, p.11) a seguinte diretriz: "capacitar a indústria nacional de material de defesa para que conquiste autonomia em tecnologias indispensáveis à defesa". Em função disso, surgiram recentemente no país várias empresas focadas no segmento de defesa, tais como Mectron e Engesa.

No tocante à Marinha do Brasil (MB), a prioridade é assegurar meios para negar o uso do mar a qualquer concentração de forças inimigas que se aproxime do Brasil por via marítima, coibir pesca ilegal, contrabando e tráfico de drogas. Impedir o uso do mar pelo inimigo é pilar da estratégia de defesa marítima do Brasil. Também e possível imaginar que a maior participação do país nas missões da ONU, a exemplo do que foi feito no Haiti, e atualmente no Líbano, requeira um melhor aparelhamento da MB. Tais prioridades trazem implicações estratégicas, táticas e operacionais para a reconfiguração das Forças Navais, incluindo as cadeias de suprimentos de componentes e equipamentos bélicos.

A independência de fornecimento externo de material bélico é tópico de fundamental importância para as Forças Armadas. Em situações de conflito, tanto interno quanto (e principalmente) externo, a garantia de apoio logístico ao referido material assegura o funcionamento adequado de equipamentos e respectivos sobressalentes instalados em navios de guerra, tais como radares de navegação, agulhas giroscópicas, ecobatímetros, hodômetros e differential global positioning systems (DGPS).

Nas últimas décadas, o nível de requisitos técnicos da MB para equipamentos de navegação marítima foi reduzido ao patamar comercial, acompanhando a tendência mundial de dispensar capacidades de resistência a choque e vibrações, o que possibilita uma nova gama de consumidores civis para os produtos nacionalizados, além de outras forças estrangeiras que utilizam sistemas similares. Por outro lado, os equipamentos para navegação instalados nos navios de guerra do Brasil são todos importados, sendo a compra efetuada por intermédio das Comissões Navais do Brasil em Washington e na Europa (CNBW e CNBE). A burocracia envolvida nesse processo torna a compra de itens de baixa complexidade tecnológica bastante demorada.

A expectativa inicial dos programas de nacionalização é a manufatura de modelos mais simples, que forneçam oportunidades para aprimoramento tecnológico progressivo, e que possam ser testados com a finalidade de realimentar os processos de produção, até ser atingido um patamar de qualidade e relação custo/ benefício compatível com os requisitos do mercado nacional, e, posteriormente, com o de clientes internacionais. O desenvolvimento de fornecedores nacionais ainda se situa, na $\mathrm{MB}$, em seus estágios iniciais, porquanto a dependência de fabricantes estrangeiros é bastante desvantajosa, restringindo-se o relacionamento com aqueles fornecedores à customização eventual de determinado item ou módulo, para atender às demandas específicas dos navios de guerra.

Há evidências empíricas e teóricas de que uma boa Gestão da Cadeia de Suprimentos (GCS) contribui para o desempenho de uma organização, independentemente do setor de atuação (SHAHABUDDIN, 2011). O conceito de GCS proposto pelo CGCSP (2005), adotado nesse estudo, destaca o papel dos fornecedores, que “...envolve o planejamento e a gestão de todas as atividades associadas à logística interna e interorganizacional, bem como a coordenação e colaboração entre todos os parceiros da cadeia, sejam eles fornecedores, prestadores de serviço ou consumidores"

A pesquisa bibliográfica realizada no âmbito deste estudo revelou uma carência de estudos sobre a GCS nas Forças Armadas Brasileiras. A pesquisa aqui apresentada situa-se no campo de estudo do uso GCS para o desenvolvimento de fornecedores nacionais. Este 
trabalho estende tal campo de investigação científica buscando responder à seguinte questão de pesquisa. Qual a contribuição que a GCS traz para o desenvolvimento de fornecedores de equipamentos bélicos? O objetivo desse artigo é analisar como a GCS pode auxiliar a MB no desenvolvimento de fabricantes nacionais de equipamentos de navegação marítima, destacando os seguintes equipamentos: radares de navegação, agulhas giroscópicas, ecobatímetros, hodômetros e DGPS.

A importância da nacionalização de equipamentos aplicáveis em navios de guerra envolve a segurança nacional, com a independência do fornecimento externo daqueles suprimentos, desenvolvendo a indústria nacional, com geração de empregos e economia de divisas. A necessidade anual de desembolso para aquisição de radares de navegação, agulhas giroscópicas, ecobatímetros, hodômetros e DGPS, dependendo da configuração desejada para os navios, pode ultrapassar a casa de US\$ 7.700.000.00, incluindo a compra de sobressalentes e serviços de instalação por parte dos fabricantes estrangeiros. Com a consolidação da nacionalização, os equipamentos brasileiros podem disputar um mercado na América do Sul que movimenta cifras anuais na casa de US\$ 40.000.000,00.

\section{REFERENCIAL TEÓRICO}

\subsection{LOGÍSTICA E GCS}

Segundo Ballou (2006), o termo "logística" aparenta ter sido cunhado pelo setor militar, com diversas vitórias e derrotas atribuídas a ela atribuídas. Como exemplo, pode-se citar a maior operação logística que o mundo até então testemunhara: a invasão da Normandia (CHRISTOPHER, 2007) e (LAMBERT; STOCK ; VANTINE, 1998).

No que tange às organizações, podemos dizer que o conceito de logística tem apresentado uma evolução: da gestão de cada atividade isolada, à visão integrada das atividades da logística inbound e da logística outbound, chegando ao conceito atual de GCS que domina a teoria e pratica na área de gestão (FLEURY; WANKE; FIGUEIREDO, 2000). Nas fases iniciais, a logística envolvia o processo de gerenciamento de compra, transporte e do armazenamento de matérias-primas, componentes e produtos acabados; visando maximizar a lucratividade, por intermédio da entrega de encomendas com o menor custo associado (CHRISTOPHER, 2007).

O conceito de gestão da cadeia de suprimentos foi apresentado no início da década de 1980 por consultores empresariais (CHRISTOPHER, 2007). Na literatura científica há vários conceitos descrevendo a GCS, variando de perspectivas lineares e mais restritivas de cadeias produtivas específicas (no limite, à díade), às estruturas em redes de relacionamentos verticais e horizontais envolvendo atores de vários níveis, incluindo as industrias correlatas (SINISALO; SALO; KARJALUOTO; LEPPANIENI, 2006) e (ZACHARIA; SANDERS; FUGATE, 2014). A partir dos anos de 2000, a SCM atraiu ainda mais a atenção dos profissionais e estudiosos da área de operações, em virtude das oportunidades geradas e também pela complexidade que envolve essa gerência (FREDERICO; MARTINS, 2014).

De acordo com Chopra e Meindl (2003), uma cadeia de suprimentos (supplychain) abrange todas as etapas direta ou indiretamente envolvidas no atendimento a um pedido de um cliente, como desenvolvimento de novos produtos, marketing, operações, distribuição, finanças e serviços pós-venda. Chandra e Kumar (2000) afirmam que a GCS se constitui em um modo de incrementar a competitividade, reduzindo incertezas e fortalecendo o atendimento ao consumidor, o que exige um relacionamento integrado com fornecedores e clientes. De acordo com Ramanathan e Gunasekaran (2014), práticas conjuntas tais como planejamento, tomada de decisões e execução de planos atingem altos níveis de desempenho nas cadeias de suprimento colaborativas, causando impacto positivo em toda a rede de cadeias.

A GCS tem por alicerces os princípios de parceria, dos quais Dyer e Singh (1998) destacaram a existência de recursos estratégicos complementares no parceiro e intenção e 
habilidade deste em estabelecer relacionamentos. A GCS também se apoia no desenvolvimento da utilização de conexões entre os elos da cadeia de suprimentos, com a finalidade de prover informações que aumentarão a eficiência de todos os seus componentes, acarretando menores custos, tempos de resposta mais rápidos e melhoria no serviço de atendimento ao cliente (HELMS; ETKIN; CHAPMAN, 2000).

\subsection{DESENVOLVIMENTO DE FORNECEDORES}

Em uma visão operacional, fornecedores são fontes evidentes de redução nos custos (BALLOU, 2006). Em linha com os objetivos da GCS, os fornecedores e os clientes alinham suas práticas de suprimento, convergindo para uma estratégia única nas cadeias (MARTINS et al., 2012). Desenvolver um fornecedor é qualquer atividade que uma empresa cliente adote com vistas à melhoria de desempenho ou capacidade do fornecedor no curto ou longo prazo (HANDFIELD et al., 2000). Segundo Hakansson e Snehota (1995), relacionamentos são o produto de um processo de interação, onde ligações entre parceiros são melhoradas, com o intuito de produzir uma orientação recíproca e comprometimento. Segundo Pires (2009), o envolvimento dos fornecedores desde a fase inicial de concepção de um produto, tende a se constituir em prática usual no universo de relações com os terceirizados na cadeia de suprimentos.

A administração de fornecedores, segundo Brown et al. (2006), engloba terceirizar áreas não essenciais ao negócio. Ao se iniciar a década de 1990, as exigências impostas pelo mercado apresentaram elevado crescimento e condicionaram muitas empresas a se concentrarem em suas atividades principais, ou nas que lhes proporcionavam maior retorno. Esse procedimento acarretou que parte do conjunto de produtos e serviços necessários à linha de produção de uma empresa fosse providenciada por um fornecedor externo, em um relacionamento colaborativo e interdependente (BROWN et al., 2006). A empresa fornecedora desenvolve e melhora, em caráter contínuo, a competência e a infra-estrutura para atender a seu cliente, que, por sua vez, abre mão de possuí-las total ou parcialmente (PIRES, 2009).

A parceria comprador-fornecedor requer que os participantes desenvolvam um nível mínimo de confiança, sem o qual a aliança está condenada ao fracasso (LEVI; KAMINSY; LEVI, 2003). Christopher (2007) corrobora esse conceito quando expõe a opinião de que os acordos de parceria e mútua disposição cooperativa são muito mais eficazes do que o tradicional relacionamento distante e, em diversas situações, antagônico. Assim, a cadeia de suprimentos transforma-se em um conjunto de organizações compartilhando dos mesmos objetivos.

Reforçando a gama de motivos para desenvolvimento de fornecedores, Dornier et al. (2010) acrescentam que, para muitas empresas, a chave para uma reestruturação coroada de êxito tem sido a concentração em competências básicas ou atividades estrategicamente importantes e o afastamento das funções não essenciais. À medida que mais organizações empregam essa filosofia, a natureza da terceirização tem se transformado radicalmente. A frequência e o volume desse tipo de aliança aumentaram e seus termos e características amadureceram. Ainda segundo esses autores, a terceirização transformou-se em atividade estrategicamente importante para diversas empresas, alterando sua dimensão funcional, pois está diretamente ligada com a logística de entrada.

A lógica básica de se terceirizar é a transferência de atividades e processos realizados internamente para fornecedores externos, podendo a empresa liberar e concentrar recursos no desempenho de seus negócios principais, e no desenvolvimento e gestão de suas competências distintivas, e nas atividades que propiciam maior retorno em termos de lucratividade (PIRES, 2009). De acordo com o conceito apresentado por Brown et al (2006), administrar fornecedores é terceirizar áreas não essenciais para a empresa. Segundo Dornier et al. (2010), a terceirização refere-se ao processo de determinar como e onde adquirir itens manufaturados e matérias-primas, o que expôs ao mundo o sucesso das empresas japonesas na década de 
1990, devido, em parte, à estrutura superior de seus processos de manufatura, destacando-se o conceito de pirâmide de fornecedores em camadas múltiplas, onde cada nível alimenta o imediatamente seguinte, até o mais diretamente ligado ao processo de produção.

Quaisquer que sejam os modos como o desenvolvimento de habilidades, conhecimento, aprendizado e técnicas se encaixem na estratégia de fornecimento, é mister não deixar de monitorar até que ponto cliente e fornecedor devem perseguir a melhoria em todos os aspectos. Não implementar tal controle representa um desperdício de recursos (BROWN et al., 2006). Cadeias de suprimento bem sucedidas serão as que foram direcionadas por uma busca permanente de soluções ganha-ganha, lastreadas por reciprocidade e confiança (CHRISTOPHER, 2007).

Desenvolver um fornecedor pode abranger a criação de um programa de investimento conjunto de treinamento, a melhoria de produtos e a avaliação do desempenho de um fornecedor é essencial para selecionar o fornecedor certo (BALLOU, 2006) e (PATTNAIK, 2013). O alinhamento de objetivos e de competências é de suma importância, assim como adequar essas grandezas à estratégia geral de negócios (BALLOU, 2006). As alianças para viabilizar estratégias compreendem benefícios e riscos, estabilidade, controle do processo decisório e perda de competências que podem ser terceirizadas e exercidas unicamente por elementos extra empresa (BROWN et al., 2006). Bensaou (1999) classifica a parceria abordada por este trabalho como "fornecedor cativo", pois o fornecedor realiza um grande investimento, ao passo que o cliente assume um baixo investimento para manter o relacionamento.

\subsection{CONSTRUTOS E CONCEITOS PROPOSTOS}

Miguel e Brito (2009) propõem alguns construtos para a SCM, derivados das visões baseada em recursos e relacional, encadeadas no trabalho de Dyer e Singh (1998). Aqueles autores desdobram a visão relacional em uma perspectiva onde, ao adotarem as práticas de gestão integrada, as empresas aumentam suas vantagens competitivas, reduzem os custos e melhoram a satisfação dos clientes para todos os participantes. Segue a descrição, pela Tabela 1, dos construtos desenvolvidos no modelo Miguel e Brito (2009), os quais serão adotados nessa pesquisa:

Tabela 1- Construtos e conceitos

\begin{tabular}{|l|l|}
\hline \multicolumn{1}{|c|}{ Construto } & \multicolumn{1}{c|}{ Definição } \\
\hline Colaboração & $\begin{array}{l}\text { Viabilidade da colaboração MB/ Empresa, proporcionando } \\
\text { melhor eficiência e disponibilidade dos equipamentos. }\end{array}$ \\
\hline Relacionamento de longo prazo & $\begin{array}{l}\text { Fatores que auxiliam/ deterioram a relação; papel da redução da vi } \\
\text { dos equipamentos. }\end{array}$ \\
\hline Compartilhamento de riscos e retornos & Óbices e vantagens para os dois parceiros. \\
\hline Comunicação & $\begin{array}{l}\text { Troca constante de informações, dados e registros de desemp } \\
\text { queinfluenciam projeto, instalação e manutenção dos equipamento }\end{array}$ \\
\hline Compartilhamento de visões e objetiver & $\begin{array}{l}\text { Possibilidade de os parceiros terem os mesmos resultados como } \\
\text { como atendimento aos mesmos cronogramas de manutenç } \\
\text { substituição de equipamentos. }\end{array}$ \\
\hline Integração de processos & $\begin{array}{l}\text { A troca de informações e experiências propiciando redução dos } \\
\text { investimentos causados por superposição de atividades. } \\
\text { Terceirização. }\end{array}$ \\
\hline Especificidade de ativos & $\begin{array}{l}\text { Capacitação conjunta dos parceiros, intercâmbio de treinamento, } \\
\text { ecomplementação de recursos. Instalação de postos de } \\
\text { atendimento dofornecedor dentro das Bases Navais. }\end{array}$ \\
\hline
\end{tabular}

Fonte: Adaptado de Miguel e Brito (2009)

\section{METODOLOGIA}

O método utilizado no presente trabalho consistiu em um estudo de caso único, em função de seu critério revelador, que investigou um fenômeno contemporâneo estudado em 
um cenário real. Além disso, se referiu a uma organização que foi analisada em profundidade e intensidade. A opção pela abordagem qualitativa é justificada, pois o pesquisador participou, compreendeu e interpretou; também é adequada a classificação de observação participante, devido ao observador, deliberadamente, ter-se deixado envolver com o objeto da pesquisa.

As unidades consideradas são a Diretoria de Sistemas de Armas da Marinha (DSAM), responsável pela jurisdição de equipamentos para navegação, e uma empresa selecionada com base em seu histórico de serviços prestados à Marinha (Empresa Radiomar), com destaque para critérios de práticas de gestão de suprimentos, pontualidade, confiabilidade, suporte pós-venda e disponibilidade de seus produtos sob representação, ou seja, longo tempo entre falhas (mean time between failures - MTBF), relativos aos equipamentos abordados no presente estudo. Tal processo de análise assemelha-se à inspeção relacional, nos moldes de uma díade, onde os parâmetros individuais são considerados com reservas, em detrimento da unidade da parceria em questão.

A escolha apontou a empresa que detém o maior conhecimento e/ou potencial para se lançar no desenvolvimento de projetos de nacionalização, atendendo aos critérios de acessibilidade e de representatividade em seus campos de atuação, na ordem de 4 profissionais, e setores da Marinha que atuam na esfera de reparos e instalações, além de gerentes de obtenção de equipamentos e sobressalentes, engenheiros responsáveis pela especificação técnica para aquisição daqueles itens e profissionais envolvidos com a nacionalização de pequenos componentes, em um quantitativo também de 4 , conforme cargos descritos na Tabela 2.

Tabela 2 - Seleção de sujeitos para entrevistas

\begin{tabular}{|l|l|}
\hline \multicolumn{1}{|c|}{ MARINHA DO BRASIL } \\
\cline { 2 - 2 } & Diretor do Centro de Manutenção de Sistemas - DCMS \\
\hline Chefe do Departamento de Eletrônica - CDEDSAM \\
\hline Eerente de Meios de Superfície - GCMS \\
\hline Encarregado da Seção de Nacionalização - GNACDSAM \\
\hline Presidente - PRAD EMPRESA RADIOMAR \\
\cline { 2 - 2 } Fonte: Elaboração própria \\
\hline Diretor Comercial - DCOM \\
\hline Diretor Técnico - DTEC \\
\hline
\end{tabular}

As evidencias foram coletadas por meio de entrevistas semi-estruturadas, tendo como instrumento um roteiro de entrevista preparado a partir dos construtos selecionados para a pesquisa de campo. Todas as entrevistas forma realizadas nas instalações da $\mathrm{MB}$ e os relatos foram gravados e posteriormente transcritos. Os dados foram tratados por meio da analise de conteúdo categorial (BARDIN, 1977).

\section{APRESENTAÇÃO E DISCUSSÃO DOS RESULTADOS}

\subsection{A VISÃO DA MB}

O gerenciamento de riscos na supplychain, segundo Scanellet al. (2014), começa a se destacar como aplicação viável, pró-ativa e estratégica da SCM. A opinião dos entrevistados de que os riscos de uma empreitada de nacionalizar os equipamentos abordados nesse trabalho são bem aceitos pela $\mathrm{MB}$, vai ao encontro dos argumentos encontrados na literatura de que 
uma boa GCS pode reduzir incertezas (CHANDRA; KUMAR, 2000), e de que alianças geram compartilhamento de benefícios e riscos (BROWN et al., 2006).

A distância ao fornecedor estrangeiro, burocracia para licitações internacionais conduzidas pelas Comissões Navais, e costumeiros atrasos devidos à liberação alfandegária, constaram como dificuldades a serem abolidas, em se tratando de produtos manufaturados no país. Os resultados das entrevistas apontaram o interesse primordial da MB em desenvolver parcerias com fornecedores nacionais na área de obtenção dos equipamentos. Como benefícios percebidos pelos entrevistados foram apontados tempos de resposta mais rápidos do fornecedor, o que ajudaria a mitigar um dos principais óbices enfrentados pela organização, ou seja o tempo de aquisição e reparo. Minimizar esses tempos é apontado por Helms, Etkin e Chapman (2000) como sendo um dos atrativos que a correta troca de informações entre os parceiros proporciona.

A MB é drasticamente cerceada nesse quesito pela legislação vigente, que prioriza a política de menor preço, conforme a Lei 8.666/93. Segundo Lima, Primo e Machado (2009), cadeias de suprimento efetivas primam pela confiança e comprometimento em seus relacionamentos, devendo evoluir de uma abordagem de mercado baseada somente em governanças de mercado (preço), para relacionamentos colaborativos, de acordo com a complexidade e importância estratégica do objeto pretendido. Tal compartilhamento destacou-se dentre as expectativas dos setores consultados, sendo unânime a opinião de que quanto melhor, mais confiável, mais constante em troca de dados, experiências e feedback, mais aprimorado se torna o processo pretendido; o que está de acordo como recomendação de Ballou (2006) de que uma boa aliança logística seja embasada por confiança mútua e compartilhamento de informações.

Na opinião de Brown et al. (2006), na GCS a administração de estoque deve ser transferida para os fornecedores. Dornier et al. (2010) argumentam que essa transferência permitiria a concentração nas competências básicas, e deve ser buscada em uma reestruturação organizacional com vista à GCS. Tais recomendações estão alinhadas com o desejo manifesto pelos gestores da MB entrevistados de que o armazenamento de sobressalentes seja terceirizado, pois constitui área não essencial à sua missão. A possibilidade de instalação de postos de atendimento do fornecedor, próximos às Bases Navais espalhadas pelo território nacional, integrou o elenco de aspirações do cliente Marinha, no sentido de otimizar o tempo de fornecimento de itens, sobretudo os críticos, acelerando o processo de atendimento às necessidades dos navios.

De acordo com Pattnaik (2013), escolher um fornecedor é uma estratégia maior para a empresa operar seu processo produtivo sem dificuldades na rede de cadeias de suprimentos. Por outro lado os resultados obtidos trazem evidencias de que a MB pode ter dificuldadespara alinhara sua cadeia de suprimentos, particularmente no que diz respeito ao compartilhamento de objetivos,que Christopher (2007) e Pires (2009) classificam como de suma importância, pois gera um requisito de pleno comprometimento e confiança, a fim de que a relação clientefornecedor seja de caráter integrado e de longo prazo. Os resultados obtidos indicam que ainda prevalece uma cultura de sigilo de informações, o que pode refletir a natureza da organização,já que se trata de uma força armada.

A capacitação técnica se destacou como o principal atrativo na escolha de um parceiro para um projeto de nacionalização, que Chopra e Meindl (2003) apontam como primordial para a boa performance de uma supplychain. Também foi reportada uma preocupação com instalações físicas compatíveis com o vulto da parceria. Os resultados obtidos indicam que a MB encontra dificuldades em atender a cronogramas e programações definidos nos planejamentos de médio e longo prazos. Essas dificuldades estão associadas à no recebimento de recursos, às alterações de objetivos ocasionadas por revisões de estratégias, muitas vezes em consequência de avaliações técnicas e políticas mais aprofundadas. 


\subsection{A VISÃO DA EMPRESA}

Uma empreitada conjunta com uma Força Armada, no caso em questão a MB, foi muito bem recebida pelos responsáveis pela empresa entrevistados. Nos depoimentos obtidos os serviços de manutenção apresentaram destaque, em virtude da dificuldade de aquisição de tecnologia por uma empresa nacional. O nome "Marinha" foi citado pelos entrevistados como sendo uma excelente referência para o mercado, a exemplo do que a literatura indicou que ocorre em países que já implementaram sólidas parcerias entre Forças Armadas e indústria privada (BASTOS, 2008; BRASIL, 2004)

Por outro lado, o fornecedor escolhido para o estudo de caso antevê dificuldades, em função das projeções que a empresa faz a respeito do retorno que seu investimento. Os executivos da empresa colocaram como um dos principais empecilhos a serem transpostos as incertezas geradas pelo Governo Federal em sua política econômica. Além de um planejamento confiável, foi citada como imprescindível para a formação dessa parceria uma destinação regular de recursos para reaparelhamento da MB.

$\mathrm{Na}$ opinião dos entrevistados a aquisição de tecnologia importada também é um risco para a obtenção de retorno econômico. Entre outros aspectos, o investimento para capacitação, de modo a permitir um domínio de tecnologias cada vez mais voláteis, é relacionado na lista de obstáculos a serem ultrapassados por uma empresa que se proponha a nacionalizar equipamentos para a MB. Na medida em que a empresa avance em seu domínio tecnológico, serão necessários investimentos cada vez maiores em Pesquisa e Desenvolvimento e em engenharia de produto e processo.

A opinião recorrente dos entrevistados com o volume de compras explicita a expectativa básica do setor privado por quantidades mínimas que assegurem o retorno do investimento e uma margem de ganho previamente estipulada, além da continuidade da demanda. Essa expectativa vai de encontro à pratica de contratação atual dos órgãos ligados ao governo, que prioriza o preço em detrimento da qualidade e do relacionamento de longo prazo. Esse resultado configura-se como uma forte barreira ao estabelecido na literatura de GCS (BOWERSOX; CLOSS; COOPER, 2007; BROWNet al. 2006).

A MB é vista pelos executivos entrevistados como detentora de recursos estratégicos complementares, seja pelo prestígio ou pela experiência na operação dos equipamentos estudados nesta pesquisa. A disponibilidade dos citados recursos no parceiro é destacada por Dyer e Singh (1998) como sendo um dos princípios da parceria, que por sua vez, é um dos sustentáculos da SCM. Os referidos recursos de que a MB dispõe podem proporcionar à empresa aumento de eficiência, redução de custos, aprimoramento do produto e tempos de resposta mais rápidos (HELMS; ETKIN; CHAPMAN, 2000).

$\mathrm{Na}$ abordagem de alinhamento das respectivas logísticas, os relatos obtidos indicaram uma facilidade maior da adaptação da empresa em relação a $\mathrm{MB}$, do que o inverso, como era previsível, pois o cliente, neste caso específico é uma Força Armada. Esse alinhamento estratégico se constituiu em uma das etapas básicas de avaliação do conjunto de necessidades do cliente que o fornecedor se propõe a atender, conforme a visão de Chopra e Meindl (2003).

Os profissionais da empresa que foram entrevistados divergiram quanto a viabilidade da MB terceirizar seus estoques, seguindo as controvérsias manifestadas por diversos autores, tais como Ballou (2006), Brown et al. (2006), Christopher (2007) e Dornier et al. (2010). Segundo os argumentos contrários, a tendência do mercado de eletrônica naval é não dispor de estoques volumosos, para a obtenção de melhores retornos em outras áreas. Os resultados obtidos podem indicar uma dificuldade da empresa em associar aos produtos vendidos serviços que tenham valor para o cliente, o que é ressaltado na literatura de GCS como um diferencial nas relações de cadeias de suprimentos, particularmente nas estratégias de operação. (BROWN et al. 2006) 


\section{CONSIDERAÇÕES CONCLUSIVAS}

O objetivo desta pesquisa foi descrever como a SCM poderia auxiliar a MB no desenvolvimento de fornecedores para equipamentos comerciais usados na navegação marítima. Os resultados obtidos evidenciaram, por intermédio das informações e opiniões coletadas nas entrevistas, que os principais fatores seriam: planejamento exequível de necessidades (aquisição de equipamentos e sobressalentes), estreita troca de informações técnicas e operacionais quanto ao desempenho dos equipamentos (principalmente na fase de construção e avaliação de protótipos), e a garantia de uma demanda mínima de compras. Este último fator deveria ser acompanhado de garantias do Governo Federal visando assegurar que a MB seja contemplada com recursos anuais, que suportem um programa adequado de reaparelhamento e modernização de seus navios de guerra.

Os dados coletados permitiram levantar algumas reflexões adicionais. A nacionalização dos equipamentos usados pelas Forças Armadas é uma tendência amparada mundialmente por decisões governamentais, e por fortes parcerias com as empresas privadas. Por conseguinte, para que se obtenha e domine as tecnologias desejadas, faz-se necessário estabelecer claramente os papéis desempenhados por cada ator envolvido (governo, indústria privada, universidades, etc), no caminho já trilhado por países que fortaleceram sua indústria de defesa, transformando-a em parceira. Nos casos de sucesso investigados na literatura, as Forças Armadas abriram mão de atividades que puderam ser transferidas para as empresas, principalmente as relacionadas à manutenção, política ainda não implementada pela MB.

Nas cadeias de suprimentos situadas no exterior estudadas, as empresas estão instaladas na estrutura das próprias Forças Armadas, chegando inclusive em participação acionária do governo nas empresas de defesa. Citando como exemplo o caso italiano, o governo é dono de $30 \%$ da indústria de defesa. No Reino Unido há duas grandes empresas que se situam em todos locais inerentes à defesa, com seus representantes trabalhando dentro das Forças, em regime de parceria. No caso dos Estados Unidos, há empresas que se mantém praticamente por trabalhar apenas para o setor de defesa. No Brasil, ao contrário, ainda prevalece uma governança predominantemente comercial na relação entre Forças Armadas e empresas privadas.

Aparentemente, o caminho para nacionalização na área de defesa está bem definido por pioneiros internacionais. No entanto, alguns obstáculos foram identificados. Do ponto de vista estrutural, as restrições ocasionadas pela rápida obsolescência das tecnologias envolvidas. Os modelos de gestão, mais especificamente os mecanismos de governança adotados pela MB impõem serias barreiras para a realização de parcerias. Os depoimentos e a observação no campo evidenciam a ausência de critérios coerentes de colaboração e confiança com os fornecedores, a oscilação das prioridades atribuídas a determinadas classes de navios, e pelo redirecionamento de recursos previamente destinados. As evidencias coletadas também indicam uma preocupação excessiva com a segurança e com a posição inconteste de liderança da MB nas redes de suprimentos porventura formadas.

Mesmo com todas as barreiras institucionais e organizacionais apontadas, há evidências de que o domínio da tecnologia de equipamentos comerciais para navegação marítima, mantendo e incrementando o índice de nacionalização de seus produtos, proporcionará à indústria de eletrônica naval a possibilidade de galgar degraus imediatamente superiores, com crescente complexidade, a exemplo do que foi realizado por tantas empresas hoje mundialmente consagradas.

No cenário atual, a exigência de aderência absolutaà Lei 8.666/93, cujo foco está na busca pelo menor preço, expõe a MB a situações de baixa confiabilidade, incertezas no fornecimento, e ausência de representantes capacitados no país. Em decorrência dessa legislação dissociada da realidade específica das Forças Armadas, o cliente sofre restrições

que acarretam não conformidades facilmente elimináveis pelo desenvolvimento de uma 
parceria com a indústria nacional moldada sobre os princípios da SCM apontados na literatura.

A necessidade de políticas públicas integradas, que almejem socorrer as Forças Armadas no que tange à recomposição de seus quadros técnicos, principalmente de servidores civis, foi evidenciada. A ausência desses profissionais ocasiona gargalos na GCS, devido à distância que frequentemente se estabelece entre a tecnologia alvo e os profissionais encarregados de instalação e manutenção dos equipamentos abordados por este estudo. Além da questão da qualidade, a insuficiência numérica dos técnicos da MB foi levantada de maneira enfática pelos entrevistados. Por fim, os resultados deixam claro que o Governo Federal deve reavaliar o orçamento para o Setor de Defesa, já que a escassez de recursos torna-se fator primordial no desestímulo à maior colaboração entre a MB e o setor privado, condição indispensável para a configuração de uma GCS.

\section{REFERÊNCIAS BIBLIOGRÁFICAS}

[1] BALLOU, R. H. Gerenciamento da cadeia de suprimentos/logística empresarial. 5. ed. Porto Alegre: Bookman, 2006.

[2] BARDIN, L. Análise de conteúdo. Lisboa, Edições 70, 1977.

[3] BASTOS, E.C.S. Indústria de defesa no Brasil: algumas reflexões. Revista do Clube Militar, ano LXXXI, nº 429, MAI/JUN 2008.

[4] BENSAOU, B. M. Portfolios of buyer-supplier relationship. Sloan management review, v.40, pp 35-44, 1999.

[5] BOWERSOX, D. J.; CLOSS, D. J.; COOPER, M. B. Gestão da cadeia de suprimentos e logística. 3. ed. Rio de Janeiro: Elsevier, 2007.

[6] BRASIL, Ministério da Defesa, Secretaria de estudos e cooperação. As Forças Armadas e o desenvolvimento científico e tecnológico do país. Brasília, 2004.

[7] BRASIL, Ministério da Defesa. Estratégia nacional de defesa. 2. ed. Brasília: 2008.

[8] BROWN, S.; LAMMING, R.; BESSANT, J.; JONES, P. Administração da produção e operações: Um enfoque estratégico na manufatura e nos serviços. 2. ed. Rio de Janeiro: Campus, 2005.

[9] CHANDRA, C.; KUMAR, S. Supply chain management in theory and practice: a passing fad or a fundamental change? Industrial Management \& Data Systems, v. 100 , issue 3,2000 .

[10] CHOPRA, S.; MEINDL, P. Gerenciamento da cadeia de suprimentos. São Paulo: Pearson, 2003.

[11] CHRISTOPHER, M. Logística e gerenciamento da cadeia de suprimentos: criando redes que agregam valor. 2. ed. São Paulo: Cencage, 2007.

[12] CORRÊA, H.L.; XAVIER, L.H. Concepts, design and implementation of reverse logistics systems for sustainable supply chains in Brazil. Journal of operations and supply chain management, v. 6, $\mathrm{n}^{\mathrm{o}} 1$ January- June 2013.

[13] DORNIER, P.P.; ERNST, R.; FENDER, M.; KOUVELIS, P. Logística e operações globais: texto e casos. São Paulo: Atlas, 2010.

[14] DYER, J. H.; SINGH, H. The relational view: cooperative strategy and sources of interorganizational competitive advantage. Academy of Management Review, v.23, $\mathrm{n}^{\circ}$ 4, pp 660-679, 1998. 
[15] ELLRAM, L. M.; COOPER, M. C. Supply chain management: It's all about the journey, not the destination. Journal of supply chain management, v.8, $\mathrm{n}^{\circ} 1$, pp 1-14, 2014.

[16] FLEURY, P. F, WANKE, P., FIGUEIREDO, K. F. Logísticaempresarial: a perspectivabrasileira. São Paulo: Atlas, 2000.

[17] FREDERICO, G. F.; MARTINS, R. A. Performance measurement systems for supply chain management: How to manage its maturity. International journal of supply chain management, v.3, n², pp 24-30, 2014.

[18] HAKANSSON, H.; SNEHOTA, I. Developing relationships in business networks. Routledge, London 1995.

[19] HANDFIELD, R.; KRAUSE, D.; SCANELL, T.; MONCZKA, R. Avoid the pitfalls in supplier development.Sloan management review, Winter 2000.

[20] HELMS, M. M.; ETKIN, L.P.; CHAPMAN,S. Supply chain forecasting - collaborative forecasting supports supply chain managemennt. Business process management journal, v. 6, issue 5, 2000.

[21] JANE'S YEARBOOKS.JANE'S fighting ships 2012-2013. 116 ed. Captain Richard Sharpe, UK, 2012.

[22] LAMBERT, D. M.; STOCK, J.R.; VANTINE, J.G. Administração estratégica da logística. 3. ed. São Paulo: Vantine consultoria, 1998.

[23] LEVI, D.S.; KAMINSY, P.; LEVI, E.S. Cadeia de suprimentos projeto e gestão: conceitos, estratégias e estudo de caso. Porto Alegre: Bookman, 2003.

[24] LIMA, Y. K.; PRIMO, M. A. M.; MACHADO, F. O. Integração e relacionamento de fornecedores da indústria naval e estaleiros. XXIX Encontro nacional de engenharia de produção, Salvador, BA, 06 a 08 de setembro de 2009.

[25] MARTINS, R.S.; SOUZA FILHO, O.V.; PEREIRA, S.C.F.; DI SERIO, L.C. Alinhamento de estratégias de relacionamento fornecedor-cliente na cadeia automobilística brasileira.XXXVIEnANPAD, Rio de Janeiro, 2012.

[26] MENTZER, J. T.; DEWITT, W.; KEEBLER, J. S.; MIN, S.; NIX, N. W.; SMITH, C. D.; ZACHARIA, Z. G. Defining supply chain management. Journalof business logistics, v.22, $\mathrm{n}^{\circ} 2$, pp 1-25, 2001.

[27] MIGUEL, P. L. S.; BRITO, L. A. L. A gestão da cadeia de suprimentos e sua conexão com a visão relacional da estratégia. XXXIII EnANPAD, São Paulo, 2009.

[28] PATTNAIK, M. Fuzzy supplier selection strategies in supply chain management.Internationaljournalofsupplychain management, v.2, $\mathrm{n}^{\circ} 1$, pp 30-39, 2013.

[29] PIRES, S.R.I. Gestão da cadeia de suprimentos: conceitos, estratégias, práticas e casos. 2. ed. São Paulo: Atlas, 2009.

[30] RAMANATHAN, U.; GUANASEKARAN, A. Supply chain collaboration: Impact of success in long term partnerships. International journal of production economics, 147, pp 252-259, 2014.

[31] SINISALO, J.; SALO, J.; KARJALUOTO, H.; LEPPANIENI, M. Managing customer relationships through mobile medium - underlying issues and opportunities.System Sciences, HICSS'06. Proceedings of the 39th Annual Hawaii International Conference on, v.6, pp 112b-112d, 2006. 
[32] SCANELL, T. V.; CURKOVIC, S.; WAGNER, B. J.; VITEK, M. Supply chain risk management within the context of COSO's enterprise risk management framework.Journal of business administration research, v.2, $\mathrm{n}^{\circ} 1,2013$.

[33] ZACHARIA, Z. G.; SANDERS, N. R.; FUGATE, B. S. Evolving functional perspectives within supply chain management.Journal of operations and supply chain management, v.50, $\mathrm{n}^{\circ} 1,2014$. 